\title{
TECHNOGENIC HALOGENESIS IN THE MIDDLE TAIGA OF WESTERN SIBERIA AND EFFECTS OF SOIL SALINIZATION
}

DOI: https://doi.org/10.18509/AGB.2021.14

UDC: 504.61:665.6]:[631.42:911.52(571.1/.5)

\author{
Elena Dvurechenskya \\ Moscow City Branch of the Russian Geographical Society, Russian Federation \\ corresponding author: navrodskaya@gmail.com
}

\begin{abstract}
Technological halogenesis, as a phenomenon, was first observed in 1987 in Western Siberia by N.P. Solntseva. In this paper, the salted soils of med-taiga landscapes were studied. Differences in the formation of technogenic anomalies among different types of soils of highland swamps and forest ecosystems were identified. As examples of impacts, oil spills on pipelines and wastewater spills, as well as effluents from cluster sites, were considered. Geochemical transformation was detected by the following indicators: $\mathrm{pH}$, organic carbon, ion-salt composition. Detailed maps of dispersion halos were built. This paper focuses on the salinization process in Western Siberia, as no less important than the impact of hydrocarbons.
\end{abstract}

Keywords: oil pollution, soil salinization, West Siberian, technogenic hydrocarbons, peat soils.

\section{INTRODUCTION}

Technogenic halogenesis as a phenomenon in Western Siberia was first described by N.P. Solntseva in 1987. This article studies the issues of the saline soils of mid-taiga landscapes. Differences in the formation of technogenic anomalies among different types of high-moor peat soils and forest ecosystems are exposed. Oil spills in pipelines and wastewater spills, as well as effluents from cluster

\section{LOCATION}

The study area is located in the central part of the West Siberian Plain and includes Prirazlomnoye oilfield. The territory belongs to the continental

\section{METHODS AND AIM OF STUDY}

The soils of natural and natural-technogenic ecosystems of Big Volysyakh and Small Salym rivers interstream are considered as the research objects. To study technogenic halogenesis in the middle taiga of Western Siberia field studies were conducted in July 2019 and August 2018 (47 soil profiles) as well as analytical processing of the data obtained during the field work (98 soil samples, 397 determination samples). The combination of applied research methods made it possible to examine in detail the features of the soils of Big Volysyakh and Small Salym rivers interstream and reveal characteristic features of their geochemical transformation. Soil studies were carried out by the sites, are considered as examples of technogenic impacts. Geochemical transformation was detected by the following indicators: $\mathrm{pH}$, organic carbon \& ion-salt composition. Detailed maps of dispersion halos are charted. This work focuses on the oils salinization process in Western Siberia as no less important than the impact of hydrocarbons emissions.

moderately cold climatic zone with insufficient heat supply and excess moisture. The terrain of the area is weakly rugged, most of it is swampy.

following indicators: the content of readily soluble salts, $\mathrm{pH}$ values, organic carbon content of soils, the composition of the soil-absorbing complex $(\mathrm{Ca} 2+$, $\mathrm{Mg} 2+, \mathrm{H}+, \mathrm{Al} 3+, \mathrm{Na}+$ ), the content of $\mathrm{Cl}-$ and $\mathrm{Na}+$ ions in the aqueous extract, and the total content of oil products in soils.

Organogenic hydromorphic soils and plain soils are dominant among the studied soils.

Organogenic hydromorphic soils are represented by peat swamp soils of upland swamps and ridge hollow swamps, while soils of the plains are mainly peat humus and eluvial-gley. Swamp landscapes are mostly ultra-fresh with minimal content of minerals. Therefore, this area where the display of 
halogenesis is inherent in natural conditions in southern desert and semi-desert landscapes, was of particular interest in our research. On the research site, the swamp ryam type complexes occupy convex peaks within the interstream and differ in pine-shrub-sphagnum vegetation (Fig. 1). In the swamp of ryam type the peat soils of the upland swamps are formed. In summer, these soils are characterized by the presence of an active peat layer, devoid of gravitational moisture, and the level of soil and groundwater $20-50 \mathrm{~cm}$ on average.

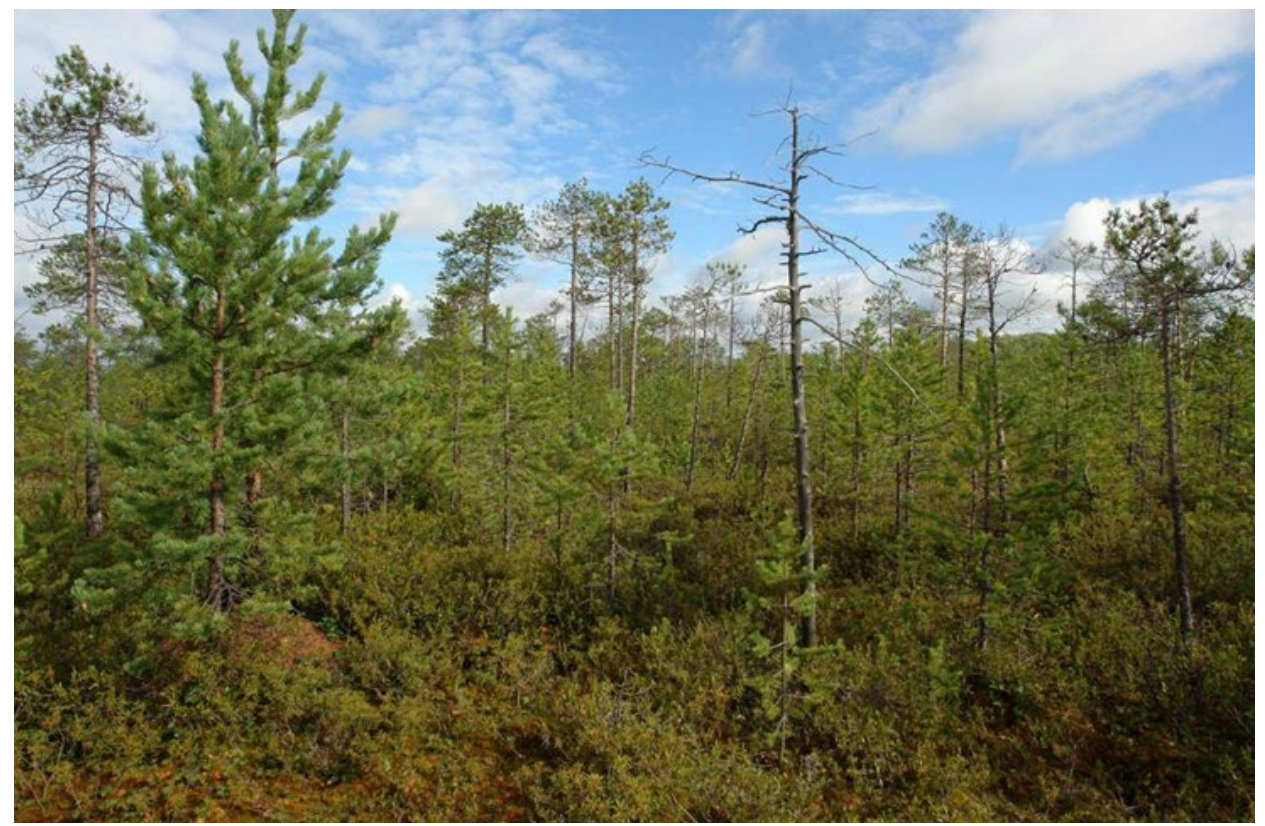

Figure 1. Swamp ryam type upland complex (photo of the article writer). The mesorelief of such swamps are characterized by convex hillocks with a height of $40-70 \mathrm{~cm}$ and a diameter of $50-100 \mathrm{~cm}$.

The distinctive characteristic of these oils is an acidic reaction along the entire profile and a low salt content. $\mathrm{Al}, \mathrm{H}, \mathrm{Cl}$ prevail in the ion-salt complex. The content of organic carbon varies from $20 \%$ to $30 \%$ and steadily increases to the bottom of the profile. Ridge-hollow swamps develop on surfaces that are homogeneous in slope. Such complexes differ in a specific mesorelief in the form of ridges and swampy hollows (Fig. 2). Stream flows (peats rivers, streams) form swamps drainage and provide differences in plant nutrition.

The main sources of readily soluble salts in the Prirazlomnoy licensed area are oil and water pipelines and cluster sites. Below we will review the differences in the geochemical transformation of soils under different kinds of impact. Swampy hollows occupy $50-60 \% \mathrm{f}$ the surface of inter stream ridge-hollow swamps (Fig. 3.9). The width of the hollows is $50-70 \mathrm{~m}$ on average. The width of the ridges is mostly about 30 metres. The ridges rise by $50-70 \mathrm{~cm}$ above the hollows. Pit-and-mound relief prevails within the ridges. By basic chemical indicators the soils of ridge-hollow swamps differ slightly from the soils of the ryam type swamps. The differences lie mainly in the degree of hydromorphism: the soils of ridge-hollow swamps are more hydromorphic. The soils of ridge-hallow swamps have an acidic reaction. $\mathrm{PH}$ values range from 4.3 to 4.6 . The salt content slightly decreases to the bottom of the profile from 0.01 to $0.005 \%$. The content of organic carbon is maximum in the upper part of the profile $(30 \%)$. In the modern period, swamping occurs mainly due to the expansion of growing sphagnum swamps. The main factor driving the transgression of swamp complexes in the middle taiga zone is the presence of the swamps themselves, which raise groundwater levels in areas adjacent to swamps. The transgression of swamps right and left is determined by the character of the relief, lithological composition of surface sediments, and the groundwater level.

Hummocks from 40 to $50 \mathrm{~cm}$ in height and from 50 to $100 \mathrm{~cm}$ in diameter are distinguished in the microrelief of such wetlands. In the tree layer of vegetation prevail pines. The height of the trees ranges from 5 to $12 \mathrm{~m}$ with the diameter of the stemss varying from 15 to $30 \mathrm{~cm}$. Shrubs actively grow on swampy dry lands. The projective coverage of the shrub layer is up to $80 \%$. The species composition of the shrub layer is dominated by blueberries, bilberries and ledum. Cranberries and bog rosemary are found in inter-point depressions. The moss layer is represented by sphagnum mosses. At the tops of the hummocks are found green mosses. 


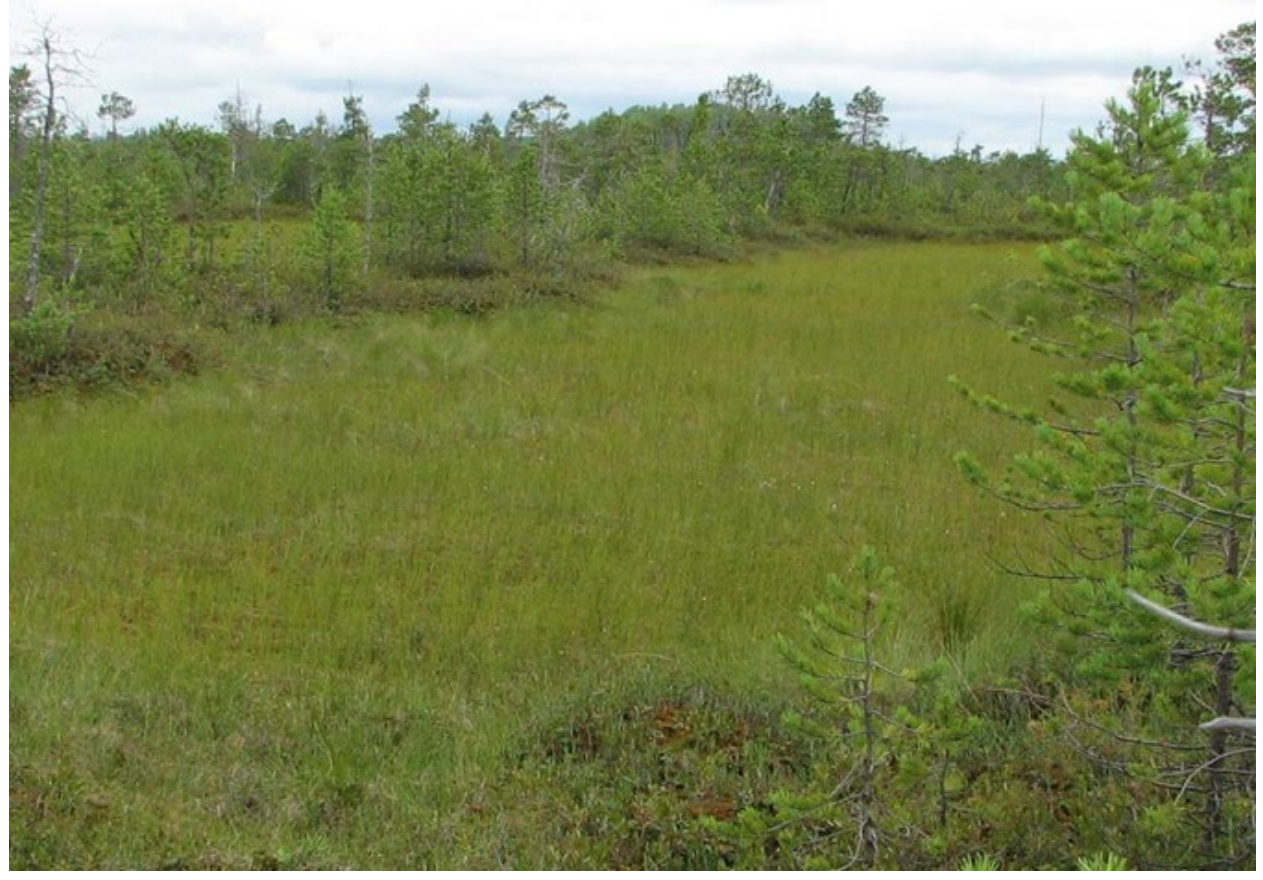

Figure 2. Ridge-hollow swamp (photo of the article`s writer).

Areas of swampy floodplains are found in the Small Salym river valley, mainly on gently sloping surfaces. The vegetation cover is represented by the species of a birch-sedge plant association. The birch grows in groups or individually, the height of the trees is $4-10 \mathrm{~m}$, the diameter of the trunks is $5-15$ $\mathrm{cm}$. The grass cover is dense, the degree of projective cover is up to $80 \%$. In the grass layer different types of sedge and bayonet rush are dominant.

Areas of swampy dry land (high ryam) are presented by peat humus eluvial-gley soils (Khrenov, 2002).

The thickness of the peat layer of soils is $50-60 \mathrm{~cm}$. The structure of the soils profile is distinguished by the following set of horizons:

$\mathrm{O}$ - sphagnum comb of undecomposed stems of sphagnum mosses with an admixture of rhizomes of shrubs and rare wood roots. Thickness $-10-15 \mathrm{~cm}$. $\mathrm{T}$ - peat horizon. Thickness is $50-60 \mathrm{~cm}$.

\section{RESULTS}

The nature of migration and accumulation of watersoluble salts in natural landscapes depends on the characteristics of the process of technogenic halogenesis. In turn, the intensity of the latter is determined by geochemical features of reservoir fluids (their mineralization and composition) and environmental conditions (the ratio of precipitation / evaporation / the specifics of the terrain drainage are of main importance), the soil sorption properties and soil permeability.

Technogenic halogenesis occurring in humid ultrafresh swampy landscapes is environmentally most hazardous due to the significant differences in the
Sometimes, according to the degree of decomposition, it is subdivided into two subhorizons: T1 (brown or dark brown, consists of well-formed plant residues) and T2 (with a high degree of decomposition).

Ap - consists of highly decomposed plant debris; dark brown in color; unstructured.

Under the organogenic horizons lies the mineral horizon G.

$\mathrm{G}$ - divided into brown humus-glandular and rock horizons.

The soils are strongly acidic, less in gley horizons. The salt content increases to the bottom of the profile from 0.2 to $0.6 \%$. The content of organic carbon increases with depth in the peat mass, then sharply decreases in gley horizons. Easily soluble salts at the Prirazlomnoye field enter the environment, as a rule, with wastewater flows after accidents at oil pipelines, water pipelines and with drains from cluster sites as well...

salt content of the ecosystem and of the incoming pollutant stream.

The composition of highly mineralized flows on the territory of the Prirazlomnoye license area within the studied interfluve includes $\mathrm{Na}, \mathrm{Ca}, \mathrm{Mg}, \mathrm{Cl}$, which is confirmed by high values of the correlation coefficients between these elements (in the range of 0.85-0.98). Formation fluids and effluents of the Prirazlomnoy territory are characterized by relatively low salt concentrations (16-18 g/l, Goncharov, 1987), which effects in a lower overall level of salt pressure on the soil. The natural specifics of the study area determine significant 
waterlogging of soils and do not contribute to the active accumulation of water-soluble salts. On the other hand, poor drainage of the study area and, consequently, insufficient outflow of solutions together with the widespread distribution of peat bog soils with increased salt content (Guseva, 1998) create favorable conditions for the formation of high-contrast salt-induced technogenic anomalies.

Numerous studies in oil production areas show that in all-natural conditions, even with all technological requirements being met, a geochemical transformation of the soil cover occurs inevitably.

The impact of emergency wastewater spills on water conduits is associated with the influx of highly mineralized streams. In peat bog soils, the salt content increases up to $5-6 \%$. The amount of readily soluble salts depends on the volume of wastewater discharge and the characteristics of the receiving ecosystem. There are differences in the distribution of salts between the types of peat bog upland soils (appendices 8, 9.10).

Salt accumulation in the ridge=hollow swamp soils, occurs in the upper part of the soil profile. With maximum at a depth of $5 \mathrm{~cm}$ reaching $5.6 \%$ the salt content drops to $1 \%$ down the profile (Fig. 3). In the spatial breakdown, the largest amount of salts is attributed to the source of the accident.

In the ridge-hollow swamps, readily soluble salts accumulate in the ridges. This is due to the greater evaporative capacity of the solutions on the ridges on the account of their greater surface albedo and a higher hypsometric level in comparison with the hollowss. $\mathrm{NaCl}$ is dominant in the composition of salts (Pic. 3). Maximum salt concentrations are confined to the lower horizons. This is determined by the inclusion of sodium and chlorine in the composition of salts of organic acids, which are untraceable due to the lack of detection methods. The bulk of the salts is concentrated in the lower horizons of the soils in the ryam type swamps (Fig. 4), due to the predominance of the vertical waterflows. The ciontent of $\mathrm{Cl}$ in the Och horizon is $1.5 \mathrm{mg} * \mathrm{eq} / 100 \mathrm{~g}$, in the $\mathrm{T} 1$ horizon $-5 \mathrm{mg} *$ eq / $100 \mathrm{~g}$, and $\mathrm{Na} 2.5 \mathrm{mg} *$ eq / $100 \mathrm{~g}$ and $5 \mathrm{mg} *$ eq / $100 \mathrm{~g}$, respectively. The ryam type upland swamp ecosystems, on the whole, are drier than the hummock-ridge complexes, while inter-mound spaces are less flooded, though even here, the abundance of moisture is enough to wash out salts down the profile.
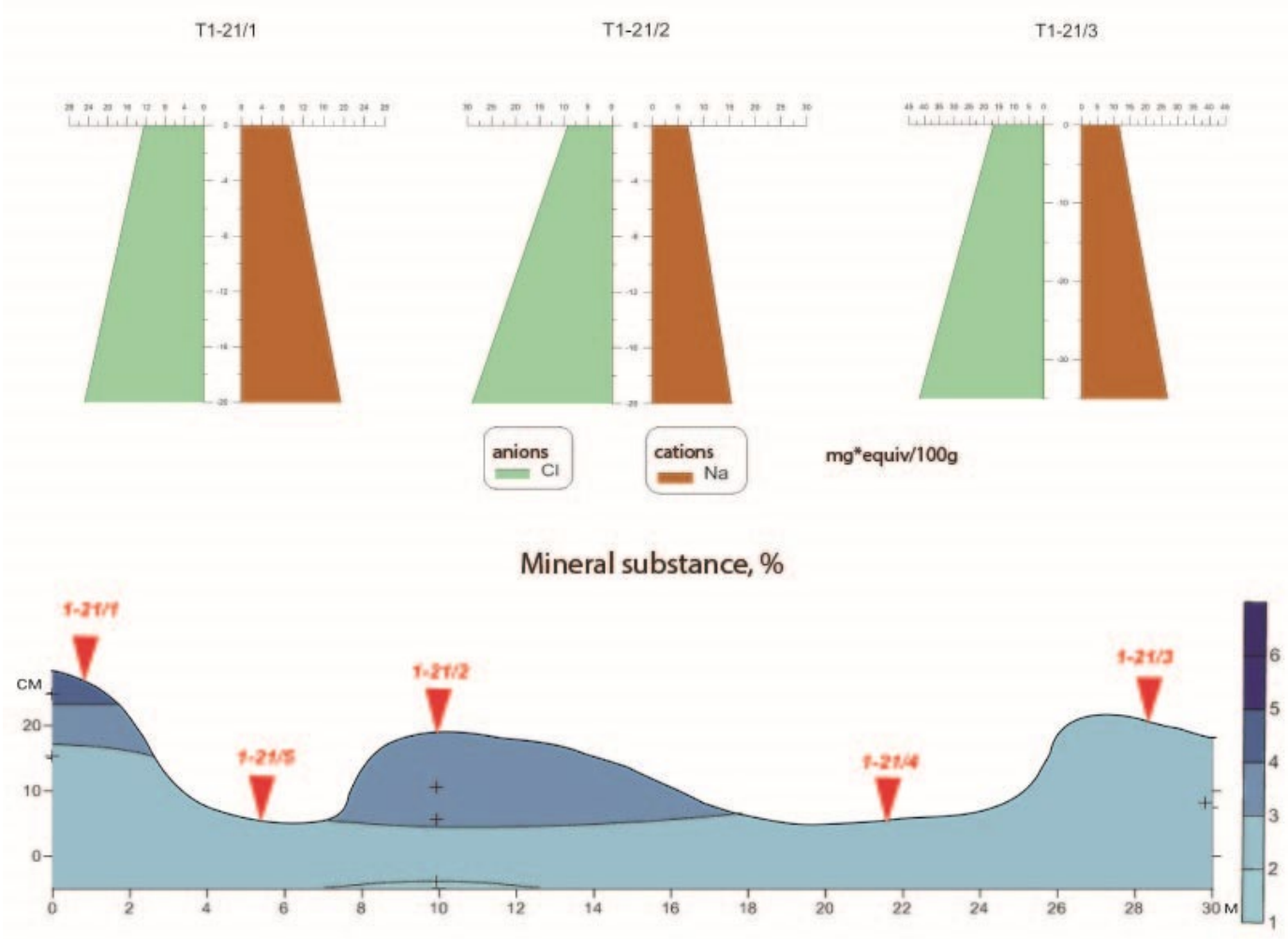

Figure 3. Changes in the content of readily soluble salts in the upland peat swamp soils of the ridgehollow swamps and the transformation of the ion-salt complex in the event of a water pipeline accident.

The distribution of alkaline acid conditions is generally characterized by a shift to the alkaline shoulder at the source of exposure. The maximum $\mathrm{pH}$ values in peat soils contaminated with sewage is 7.2 in ridge-hollow swamps. The highest alkalinity is confined to the lower horizons. In in ridge-hollow swamps, maximum alkalinity is observed in the lower parts of the ridges. This is due to the prevailing horizontal movements of swamp waters transporting the pollutant from ridge to 
ridge. In the ryam type swamps, the distribution is generally more uniformed and the area of maximum alkalization is confined to the lower horizons due to the prevailing vertical migrations of swamp waters. Thus, the alkalization of the environment in the swamps is not associated with salinization, but with hydrocarbon pollution. The influx of wastewater causes a slight increase in the BV content in the soils of the swamps (up to $4 \mathrm{mg} / \mathrm{kg}$ ). The distribution of $\mathrm{BV}$ in the ryam type swamps and ridge-hollow complexes is characterized by the location of the maximum in the lower horizons (Pic. $7,8)$. The location of the maximum of BV content coincides with the location of the areas of maximum alkalinity (Pic. 5, 6, 7, 8). The differences in the distribution of the ryam type swamps and ridge-hollow swamps are associated with the direction of swamp water movement. Weakly rugged terrains and poor drainage conditions determine the versatility of the soil cover. Within the study area, upland peat swamp and peat-podzolic soils dominate. The significant natural water cut of ecosystems, leanness of the chemical elements in composition of parent rocks (among which sands play a significant role), and the ultra-fresh composition of surface and soil-ground waters determine the chemical properties of the soils of the studied area.
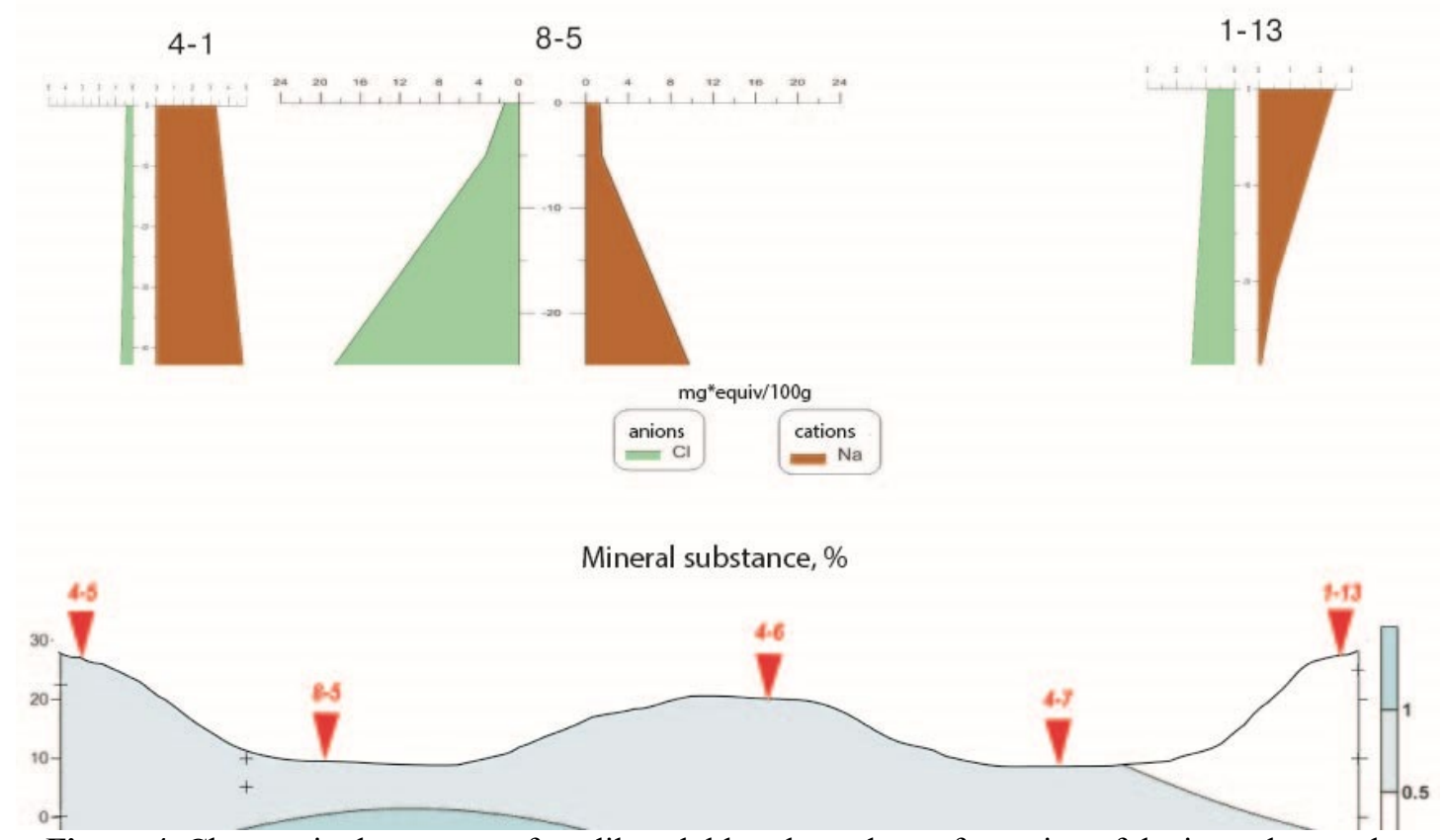

Figure 4. Changes in the content of readily soluble salts and transformation of the ion-salt complex in upland peat swamp soils of the ryam type swamps during an accident at a water pipeline.

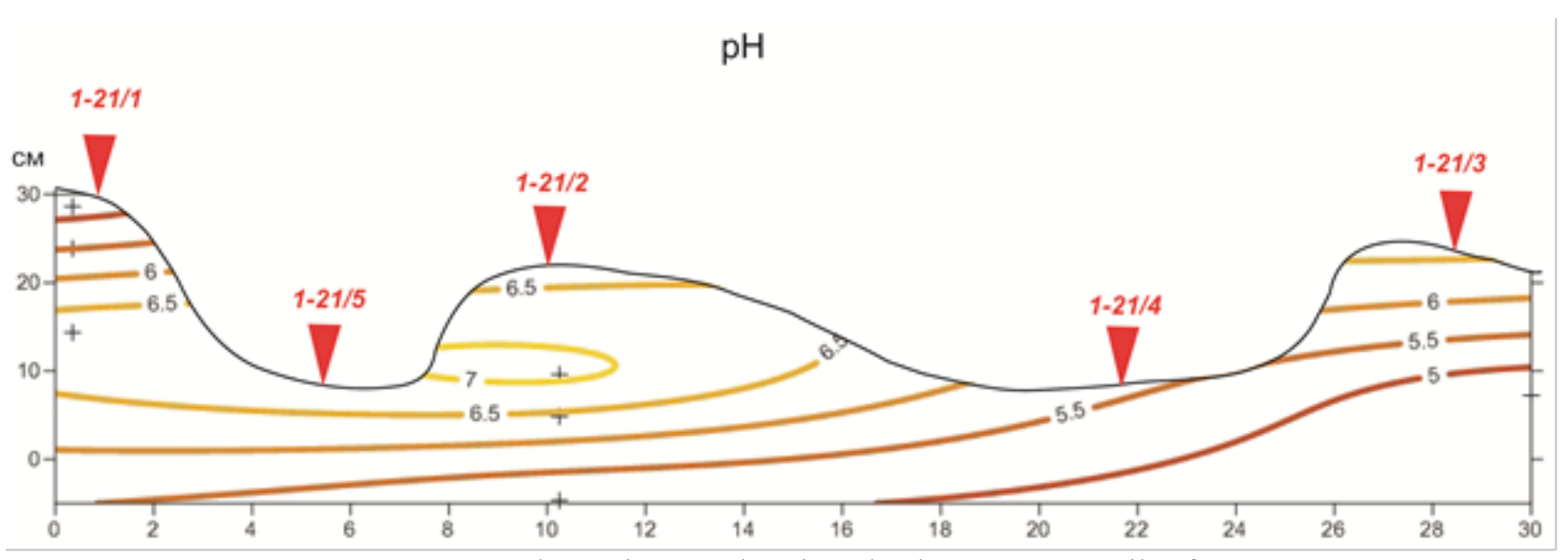

Figure 5. Change in $\mathrm{pH}$ values in upland peat swamp soils of ridge-hollow swamps during an accident at a water pipeline. 


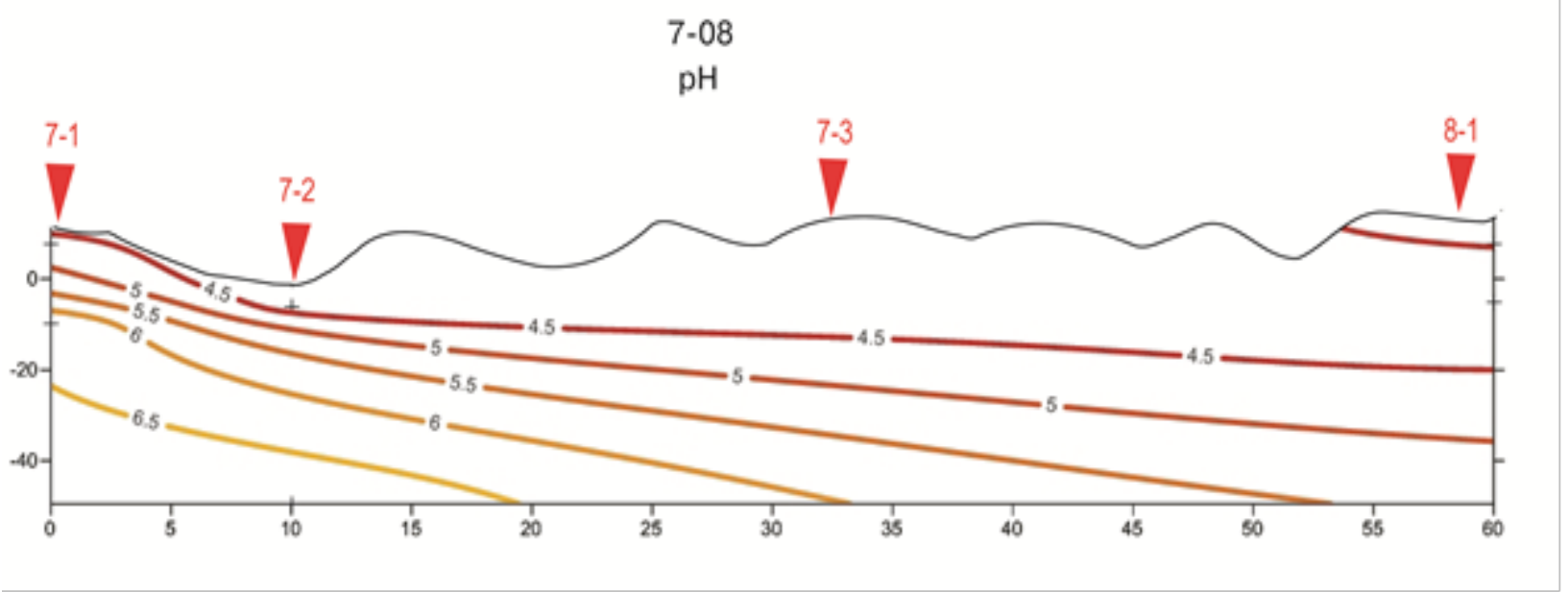

Figure 6. Change in $\mathrm{pH}$ values in upland peat swamp soils of the ryam type swamps during an accident at a water conduit.

$1-08$

Содержание битуминозных веществ, Mr/kr

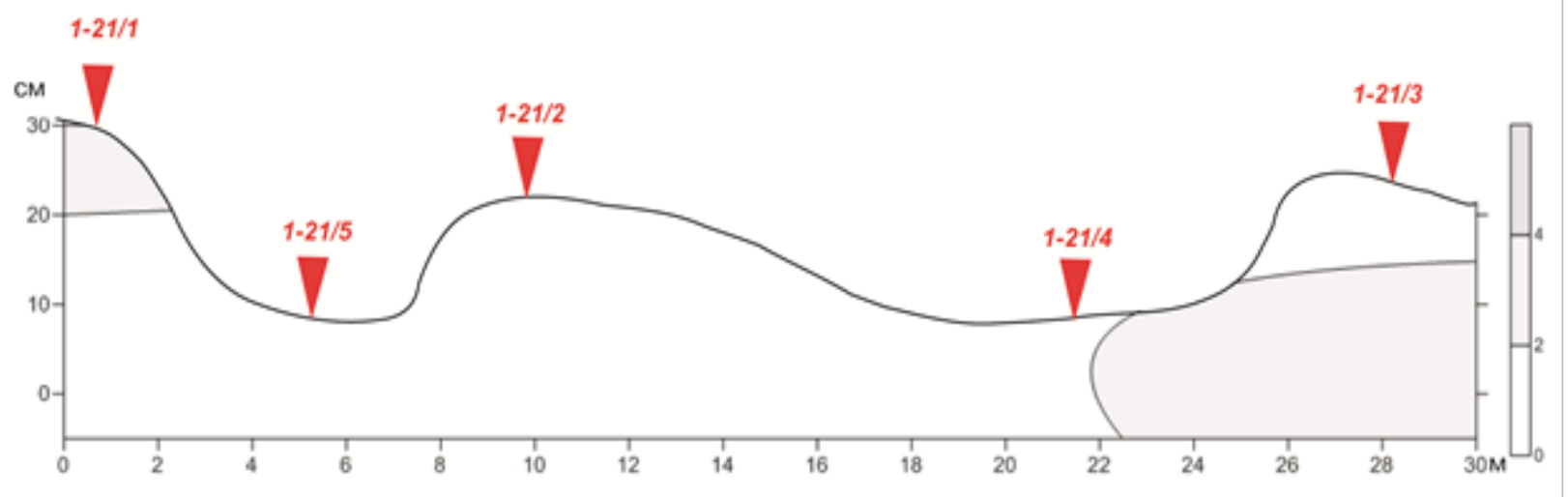

Figure 7. Lateral distribution of bituminous substances in upland peat swamp soils of ridge-hollow swamps during an accident at a water conduit.

Содержание билуминозных веществ, мr/кr

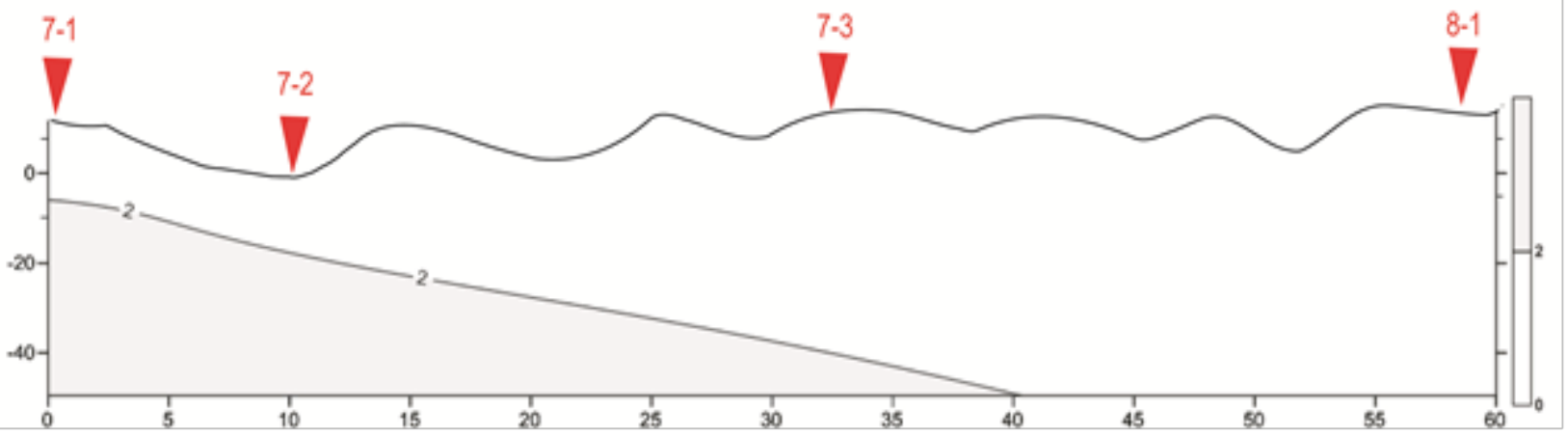

Figure 8. Lateral distribution of bituminous substances in upland peat swamp soils of the ryam type swamps during an accident at a water pipeline. 
In the course of the research, some similarities and differences in the nature of the distribution of pollutants among the soils of the middle taiga of Western Siberia were determined.

1. Migration and accumulation of readily soluble salts in organogenic soils mainly depends on the micro relief of swamps and the direction of swamp water movement.

2. In the ridge-hollow swamps, contamination is distinguished by a greater spatial distribution than in the ryam type complexes. Ridges stand as mechanical barriers to the migration of pollutants. In ryam type swamps which receive precipitation nutrition, areas of maximum contamination shift to the lower horizons.

3. In peat humus eluvial-gley soils, pollution spreads evenly in the peat mass to the mineral gley horizon.

4. Easily soluble salts are concentrated in the lower horizons in all studied soils, because of their greater mobility.

5. The lateral distribution of readily soluble salts in swamps depends on the degree of their hydromorphism. In more humid ridge-hollow swamps, salts spread over larger areas and their average concentration is lower than in ryam type complexes, where salt accumulations are of local type.

6. For any type of pollution in the ion-salt complex, the proportion of chlorine and sodium increases by a big ratio in all types of the studied soils. Differences in distribution of chlorine and sodium are associated with the presence and thickness of organogenic horizons and the degree of hydromorphism. In ridge-hollow swamps, chlorine spreads over larger distances from the source of exposure (up to $100 \mathrm{~m}$ ) than sodium (up to $50 \mathrm{~m}$ ). In the ryam type swamps, differences in the distribution of chlorine and sodium are smoothed out $(20 \mathrm{~m}$ and $30 \mathrm{~m}$, respectively). In peat and alluvial-gley soils chlorine distribution is correspondent to sodium distribution in the mineral horizons and in organogenic soils chlorine spreads for greater distances than sodium $(35 \mathrm{~m}$ and $30 \mathrm{~m}$ respectively.,

7. Transformation of alkaline acid properties is associated with alkalization of acidic and weakly acidic organogenic and mineral soils under various kinds of impact. In swampy soils, alkalization is more significant (up to 6.5-7.0) than in soils of automorphic compositions (up to 6.0 ).

The revealed patterns in the geochemical and microbiological transformation of soils of the middle taiga of Western Siberia under the impact of technogenic hydrocarbons and readily soluble salts must be taken into account when planning OSR (oil spill response). Taking into account differences in the nature of the impact on different types of soils may be economically beneficial.

\section{REFERENCES}

[1] Arinushkina E. V., A Manual of Chemical Analysis. Izd. Mosk. Gos. Univ., Moscow, 1970 [in Russian]

[2] Buzmakov S. A., S. M. Kostarev Transformation of geosystems in the oil production areas / Izvestiya vuzov. Neft i gas. News of higher education ..., 2004

[3] IUSS Working Group WRB, 2015. World Reference Base for Soil Resources 2014, update 2015. An international soil classification system for naming soils and creating legends for soil maps. World Soil Resources Reports No. 106 (2014). https: //doi.org/10.1017/S0014479706394902.

[4] Glazovskaya M. A., Methodological Bases of Assessment of Ecological-Geochemical Tolerance of Soils to Technogenic Influences. Mosk. Gos. Univ., Moscow, 1997 [in Russian]

[5] Pikovskii Yu. I., Natural Technogenic Streams of Hydrocarbons in the Environment. Mosk. Gos. Univ., Moscow, 1993 [in Russian]

[6] Solntseva N. P., Oil Recovery and the Geochemistry of Natural Landscapes. Izd. Mosk. Gos. Univ., Moscow, 1998 [in Russian] 